\title{
Adjustments in the forcing-feedback framework for understanding climate change
}

Article

Published Version

Sherwood, S. C., Bony, S., Boucher, O., Bretherton, C., Forster, P. M., Gregory, J. M. and Stevens, B. (2015) Adjustments in the forcing-feedback framework for understanding climate change. Bulletin of the American Meteorological Society, 96 (2). pp. 217-228. ISSN 1520-0477 doi: https://doi.org/10.1175/BAMS-D-13-00167.1 Available at https://centaur.reading.ac.uk/38337/

It is advisable to refer to the publisher's version if you intend to cite from the work. See Guidance on citing.

To link to this article DOI: http://dx.doi.org/10.1175/BAMS-D-13-00167.1

Publisher: American Meteorological Society

All outputs in CentAUR are protected by Intellectual Property Rights law, including copyright law. Copyright and IPR is retained by the creators or other copyright holders. Terms and conditions for use of this material are defined in the End User Agreement. 


\section{CentAUR}

Central Archive at the University of Reading

Reading's research outputs online 


\title{
ADJUSTMENTS IN THE FORCING- FEEDBACK FRAMEWORK FOR UNDERSTANDING CLIMATE CHANGE
}

\author{
by Steven C. Sherwood, Sandrine Bony, Olivier Boucher, Chris Bretherton, \\ Piers M. Forster, Jonathan M. Gregory, and Bjorn Stevens
}

More intensive analyses of climate simulations reveal a need to revise definitions of forcing and feedback and to recognize the new concept of rapid adjustments.

$\mathrm{T}$ he traditional and now ubiquitous framework for understanding global climate change involves an external forcing, a response whereby the climate

AFFILIATIONS: SHeRWOOD-Climate Change Research Centre, and Australian Research Council Centre of Excellence for Climate System Science, University of New South Wales, Sydney, New South Wales, Australia; BONY AND BOUCHER-Laboratoire de Météorologie Dynamique/IPSL, Université Pierre et Marie Curie, Paris, France; BRETHERTON-Department of Atmospheric Sciences, University of Washington, Seattle, Washington; FORSTER-School of Earth and Environment, University of Leeds, Leeds, United Kingdom; Gregory - National Centre for Atmospheric Science, University of Reading, Reading, and Met Office Hadley Centre, Exeter, United Kingdom; SteVens-Max Planck Institute for Meteorology, Hamburg, Germany

CORRESPONDING AUTHOR: Steven C. Sherwood, Climate Change Research Centre, University of New South Wales, Level 4, Matthews BIdg., Sydney NSW 2052, Australia.

E-mail: ssherwood@alum.mit.edu

The abstract for this article can be found in this issue, following the table of contents.

DOI:10.1175/BAMS-D-13-00167.1

In final form 26 June 2014

(c)American Meteorological Society system opposes the forcing in order to regain equilibrium, and feedbacks that amplify or damp the response (National Research Council 2005). The concept is most often applied to the global-mean surface temperature $\bar{T}$, where the external forcing is a radiative perturbation (effective power input) $d \bar{F}$, and $d \bar{T}$ is the change in $\bar{T}$ produced by $d \bar{F}$ at the new equilibrium. ${ }^{1}$ This new equilibrium is achieved when the system response has caused a change $d \bar{R}$ in net rate of energy loss by the planet that balances the effect of the imposed perturbation-that is, $\bar{N}=d \bar{F}-d \bar{R}=0$, where $\bar{N}$ is the net power into the planet from space. Feedback arises because there are various quantities $X_{i}$ (e.g., atmospheric water vapor or sea ice cover) that depend on $\bar{T}$ and alter the planetary energy budget. The new equilibrium encompasses all of their effects as well:

$$
d \bar{R}=d \bar{T}\left(\frac{\partial \bar{R}}{\partial \bar{T}}+\sum_{i} \frac{\partial \bar{R}}{\partial X_{i}} \frac{d X_{i}}{d \bar{T}}\right)=d \bar{F}
$$

\footnotetext{
${ }^{1}$ Following the custom in climate literature, we use "equilibrium" in the loose sense of a system that is in a statistically steady state of energy balance. This is not a strict equilibrium, since Earth is constantly generating and exporting entropy.
} 
The ratio $(d \bar{R} / d \bar{T})^{-1}$ is called the "climate sensitivity parameter" (the "equilibrium climate sensitivity" being usually defined as $d \bar{T}$ for a forcing equivalent to a doubling of $\left.\mathrm{CO}_{2}\right)$. The term $(\partial \bar{R} / \partial \bar{T})$ is the "Planck response," or the change that $\bar{R}$ would undergo if the climate system behaved as a blackbody with no feedbacks. The blackbody system is stable to radiative perturbations because $(\partial \bar{R} / \partial \bar{T})>0$. This traditional approach is illustrated in Fig. $1 b$.

There are ambiguities across disciplines in what is meant by "feedback," a concept well known in electronics and control theory (Bates 2007). We will follow the usual custom of detailed climate feedback analysis studies (see Hansen et al. 1984; Schlesinger

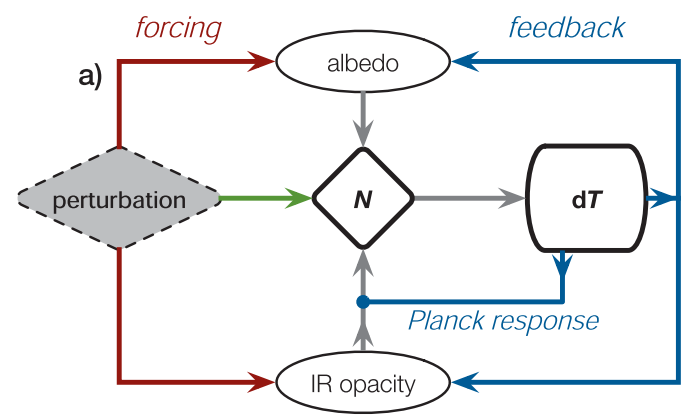

b)
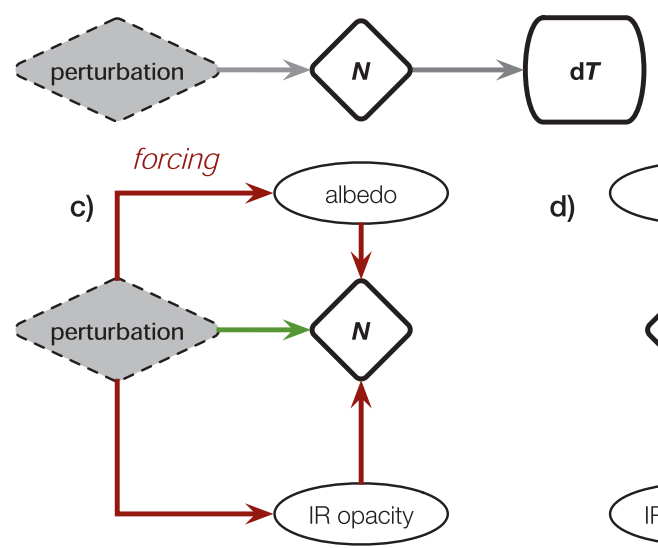

d)

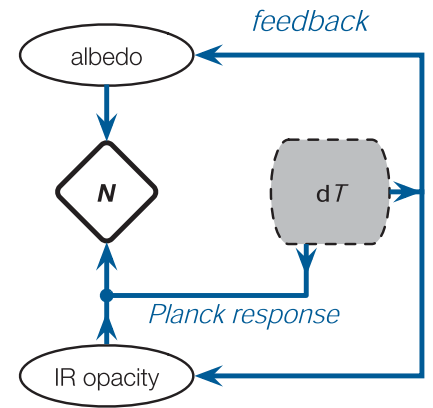

FıG. I. Diagram showing forcing-feedback concepts for global temperature and methods of diagnosing them. (a) Full system, with shortwave albedo effects in the top part and longwave in the bottom part. Traditionally defined forcing occurs via green arrow (in the case of solar forcing) or red arrows (other forcings) from perturbation to the TOA energy imbalance $\overline{\mathbf{N}}$. Adjustments also occur via red arrows. Feedbacks occur via blue arrows, with the Planck response shown by the direct arrow from $d \bar{T}$ to $\bar{N}$. Feedbacks and adjustments can be diagnosed simultaneously by the regression method. (b) Traditional view of the Planck system with no adjustments (nor feedbacks). (c),(d) Reduced atmosphere-only system with fixed SST. Adjustments can be diagnosed by observing change in $\overline{\mathbf{N}}$ after applying a perturbation with SST fixed (c); feedbacks can be diagnosed by observing changes in $\bar{N}$ after changing the SST with no (other) perturbation (d). and Mitchell 1987; Soden and Held 2006) by referring the amplifying role of a system property $X_{i}$, quantiis stable if the sum of the $\alpha$ is smaller than the Planck response. $^{2}$ The forcing-feedback paradigm has helped establish, for example, the dominant role of water vapor in amplifying global temperature change and the role of clouds in accounting for its uncertainty

Many potential feedbacks within the Earth system can be conceived, involving system components having a wide range of characteristic response times

(Dickinson and Schaudt 1998; Jarvis and Li 2011). Clouds and water vapor can respond to climate changes in days to weeks, whereas the deep ocean or ice sheets may require centuries or millennia. Feedbacks that are not fast enough to fully keep pace with responses of interest, because of the involvement of a slowly varying component such as the deep ocean or ice sheets, may appear to have timevarying strengths (e.g., Senior and Mitchell 2000); those may be better treated as exogenous forcings in transient calculations. The "equilibrium" (sometimes called "Charney") climate sensitivity (ECS) has become the standard measure of the climate sensitivity of the Earth system relevant to the anthropogenic warming problem. It was adopted from early slab ocean model experiments that were run to a less-complete equilibrium in which ice sheets, vegetation, and atmospheric composition were all specified. The paradigm can,

\footnotetext{
${ }^{2}$ Alternatively, the Planck response can also be considered as a strong negative feedback that is more direct and simpler than the others. This avoids giving it a special status and thus makes (1) more symmetrical (Gregory et al. 2009), in the sense that the system is stable if the sum of all the feedbacks, including the Planck response, is negative. However, use of the word "feedback" to describe the Planck response is confusing because there is nothing being "fed back upon."
} 
however, be extended to include, for example, changes to natural sources of $\mathrm{CO}_{2}$ as "carbon cycle" feedbacks (e.g., Gregory et al. 2009; Arneth et al. 2010; Raes et al. 2010). Additional feedbacks not considered in the ECS will enter on longer (e.g., geologic) time scales.

In applying (1) to the global climate, one normally assumes that all partial derivatives represent constants of the climate system, but this implies at least two bold assumptions. The first is that responses vary linearly with perturbation amplitudes (or, equivalently, are not state dependent). Formally, this must hold for sufficiently small perturbations but possibly not for multiple doublings of $\mathrm{CO}_{2}$, as some feedbacks may become stronger or weaker in significantly different climates (Crucifix 2006; Caballero and Huber 2013; Colman and McAvaney 2009).

The second assumption is that all responses are uniquely determined by the scalar $d \bar{T}$ regardless of how the temperature change is brought about-a situation that may be called fungibility. Complete fungibility requires either that temperature changes always occur with the same spatial and seasonal pattern or that different patterns produce the same $d \bar{R} / d \bar{T}$, where $d \bar{R}$ is the change in global-mean and annualmean radiation balance. However, this will not be the case, since different forcings will generally produce different warming patterns. Moreover, during transient warming regardless of how it is forced, some parts of the ocean may warm more slowly than others, temporarily producing anomalous warming patterns. In the absence of feedbacks, these pattern differences should not strongly affect the paradigm, since the Planck nonlinearity is sufficiently weak (Bates 2012). Many quantities $X$ that affect the global radiation budget, however, are sensitive to spatial or seasonal variations in temperature. This sensitivity lies at the root of difficulties that have emerged over the years with the traditional framework (Hansen et al. 1997).

WHY ADJUSTMENTS? The radiative forcing concept is, in effect, a "common currency" that we may use to compare various types of perturbation: emissions of $\mathrm{CO}_{2}$ or other pollutants, changes in land use, solar activity, etc. The concept is useful only to the extent that it accurately predicts the magnitude of the response without having to worry about any other details of the perturbation - that is, insofar as feedbacks are independent of the perturbation.

While one might imagine that the instantaneous impact of a perturbation on the top-of-atmosphere (TOA) radiation balance would be a good measure of its radiative forcing, early studies quickly recognized that this measure was not optimal. The temperature of the stratosphere, in particular, was not closely tied to that of the surface. For example, it warms under a positive solar forcing yet cools under a positive greenhouse gas forcing (Fels et al. 1980), therefore requiring the surface and troposphere to warm more to balance the same instantaneous TOA net flux perturbation (Hansen et al. 1997). This problem was resolved by allowing for a "stratospheric adjustment" prior to calculating the radiative forcing, which has been the standard approach at least since the first Intergovernmental Panel on Climate Change (IPCC) report (Houghton et al. 1990).

Recent work reveals that heterogeneous responses also occur within the troposphere and can produce similar but more subtle problems. Some of the most

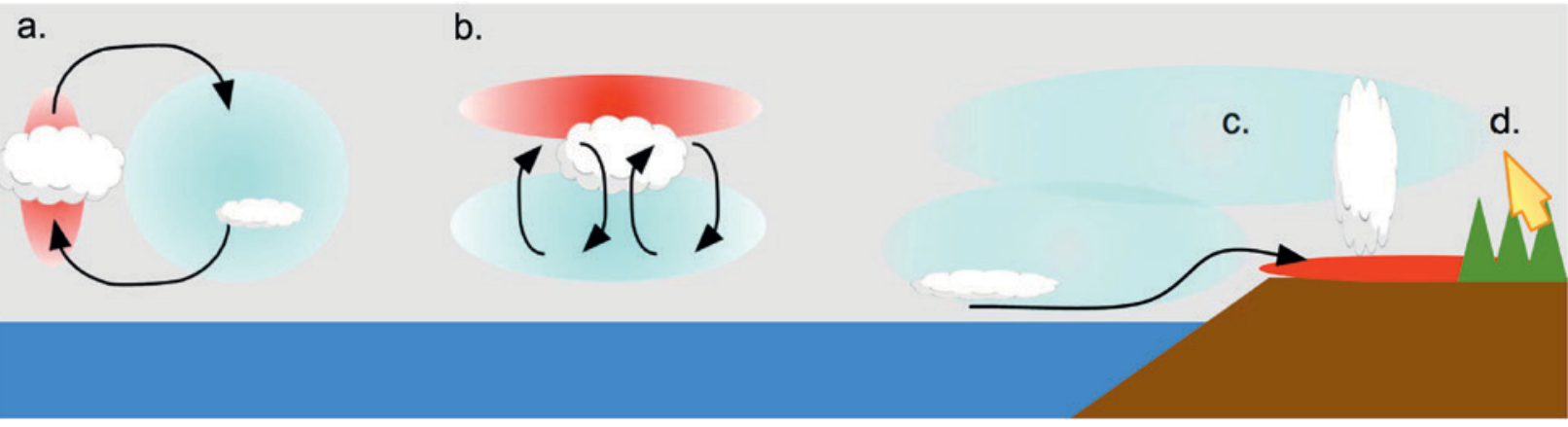

FIG. 2. Several examples of forcing adjustment mechanisms. (a) Solar, aerosol, and greenhouse gas perturbations; each can cause horizontal variations (red/blue regions) in net radiative heating of the atmosphere, which can drive circulations that alter cloud cover regionally and possibly change the global-mean radiative effect of clouds, modifying the conventional radiative forcings of these perturbations. (b) These perturbations can also cause vertical variations in the heating rate, altering atmospheric stratification, and affecting convection and local cloud development. (c) Perturbations may affect land and ocean surfaces differently, further affecting cloud cover. (d) $\mathrm{CO}_{2}$ and aerosol perturbations can increase the growth of plants (affecting land albedo) or increase their water use efficiency, affecting fluxes of water vapor (yellow arrow) and ultimately cloud cover. 
important mechanisms by which this can occur are illustrated in Fig. 2. For example, increasing the concentration of $\mathrm{CO}_{2}$ in the atmosphere affects longwave radiative fluxes and slightly warms the mid- and lower troposphere, even with no surface temperature change (see Fig. 2b). In models this subtle change in stratification and relative humidity reduces mid- and low-altitude cloud cover (Fig. 3), further altering the TOA net flux even before any global warming or cloud feedbacks take place (Andrews and Forster 2008; Gregory and Webb 2008; Colman and McAvaney 2011; Kamae and Watanabe 2012; Wyant et al. 2012). This change in cloud cover is quite different to that which occurs subsequently owing to the increase in $\bar{T}$ (cf. Figs. 3a,b). Likewise, any forcing that is horizontally inhomogeneous (e.g., changes in tropospheric ozone or aerosols; discussed below) or that significantly affects the tropospheric radiative cooling will drive changes in atmospheric circulation that may alter the planetary albedo by changing patterns of cloud cover. Conceptually, these complications are no different from the one long recognized for the stratosphere.

We refer to changes that occur directly due to the forcing, without mediation by the global-mean temperature, as "adjustments" and the accordingly modified top-of-atmosphere radiative imbalance as the "effective" radiative forcing, following Boucher et al. (2013). Their role is illustrated in Fig. 1a.

Most adjustments are rapid, but there is no fundamental time scale that separates rapid adjustments from feedback responses. The time scales of the two can, in principle, overlap significantly. Some adjustments can, for example, occur through state variables $X$ that respond very slowly [e.g., vegetation cover or soil humidity responses to $\mathrm{CO}_{2}$-induced stomatal closure (Doutriaux-Boucher et al. 2009), or aerosolinduced diffuse sunlight (Mercado et al. 2009; see Fig. 2d), or responses involving stratospheric composition and chemistry]. Meanwhile, some feedbacks, such as the water vapor feedback, can be triggered by warming of the land and atmosphere (Colman and McAvaney 2011) that occurs within days or weeks of an applied forcing. Indeed, the original stratospheric adjustment requires several months to complete and has to be calculated by a special model run with the troposphere and surface held fixed. However, the largest tropospheric adjustments are likely due to changes in clouds driven by changes in tropospheric radiative fluxes and appear to occur within days (Dong et al. 2009).

\section{ADJUSTING OUR VIEW OF AEROSOLS.}

It turns out that the climate community has been grappling with tropospheric adjustments for years but without calling them by this name: they play a dominant role in the climatic impact of aerosols. One example is the "semidirect effect" of aerosols, triggered by the uneven distribution of tropospheric radiative heating by the aerosol. This can subtly alter atmospheric stability, which will affect convection (Fig. 2b), and because it is horizontally heterogeneous, it can drive circulations (Fig. 2a) that alter both the global cloud radiative effect and patterns of temperature and rainfall. This response should be regarded as a rapid adjustment to aerosol perturbations to the radiation field, since it occurs even in the absence of a change in $\bar{T}$.

Likewise, the cloud-mediated (or "indirect") impact of aerosols, which serve as cloud condensation nuclei (CCN), on climate involves rapid adjustments. This impact begins with an increase in the number of
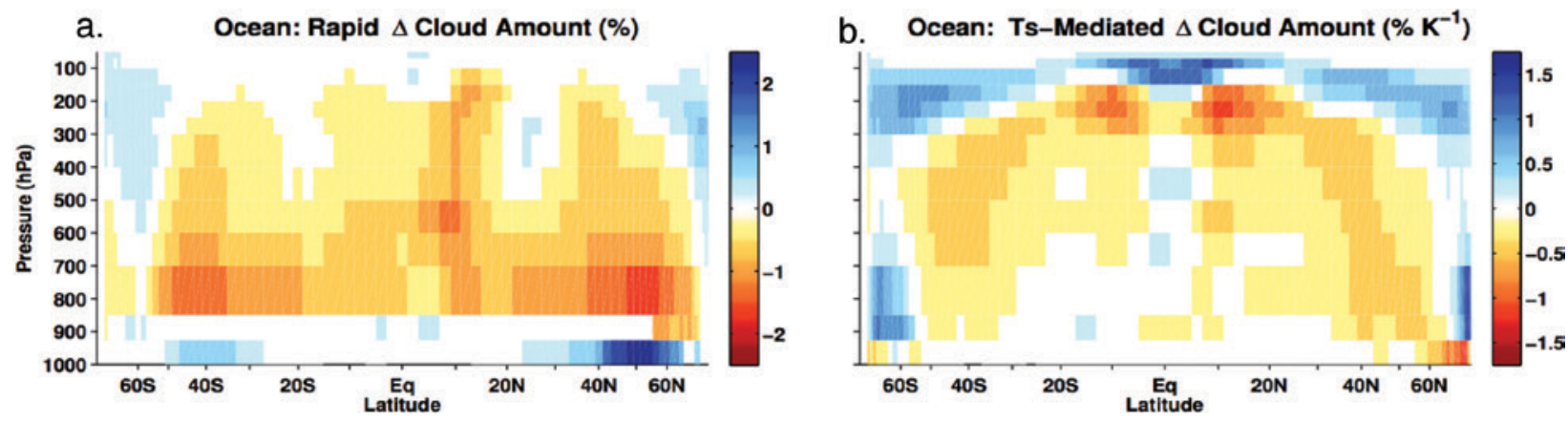

FIG. 3. Response of zonal-mean cloud cover over oceans to (a) a quadrupling of $\mathrm{CO}_{2}$ (with warming effects removed) and (b) warming (with $\mathrm{CO}_{2}$ effects removed), averaged over several GCMs, determined by the regression method. Because cloudiness is generally reduced in both cases, these responses produce increased effective radiative forcing and positive cloud feedback, respectively, although the details of the cloud changes vary among models and can be seen here to differ significantly between the adjustment and feedback responses. Reproduced from Zelinka et al. (20I3). 
nucleated droplets that, in the absence of any changes to the water content or circulation of air within the cloud, would produce a cloud with higher albedo (often called the "Twomey effect"). Model studies indicate, however, that the knock-on effects that occur via changes in the flow field or the microphysical evolution of clouds can lead to final changes in albedo that differ substantially from this initial droplet number effect. A number of such knock-on effects have been articulated in the literature, including "lifetime effect," liquid water path effect, etc. Most of these are based on idealized conceptual models, and their applicability to real clouds remains controversial (Boucher et al. 2013).

The initial and the various knock-on effects are often conceptualized as each having distinct physical significance, but in more realistic simulations, it is typically not possible to distinguish them individually, and the assumptions under which they were deduced often do not hold. Only their combined effect can be properly diagnosed. We argue that the subsequent change in $\bar{T}$ is a response to this net radiative effect of aerosol-the aerosol effective radiative forcing (ERF), which includes the initial droplet number effect and all adjustments. This concept is not new, and has been referred to in the literature before as a quasi forcing (Rotstayn and Penner 2001) or as a radiative flux perturbation (Lohmann et al. 2010).

In both the $\mathrm{CO}_{2}$ and aerosol cases, adjustments are more uncertain than instantaneous forcings because they involve cloud and other dynamical responses that models may not calculate reliably. Regardless of this, models suggest these effects can be large, so they cannot be ignored.

\section{WAYS OF DEFINING AND CALCULATING} ADJUSTMENTS. The ERF concept is motivated mainly by the desire to improve fungibility within the forcing-response framework-that is, minimize the quantitative differences of $d \bar{T}$ to various types of forcing $d \bar{F}$. Ideally, we would choose an adjustment framework that optimizes this, aiming for the ERF to be the forcing experienced by the system when $d \bar{T}=0$. There is, however, no unambiguous way to specify this, because regionally heterogeneous surface temperature changes occur immediately after a forcing is applied.

Two common approaches are available for quantifying the adjustment, with different advantages and disadvantages. The first or "regression method" (sometimes called the Gregory method) is to regress the net TOA flux perturbation $\bar{N}$ onto $d \bar{T}$ in a transient warming simulation, yielding a plot (see Fig. 4)

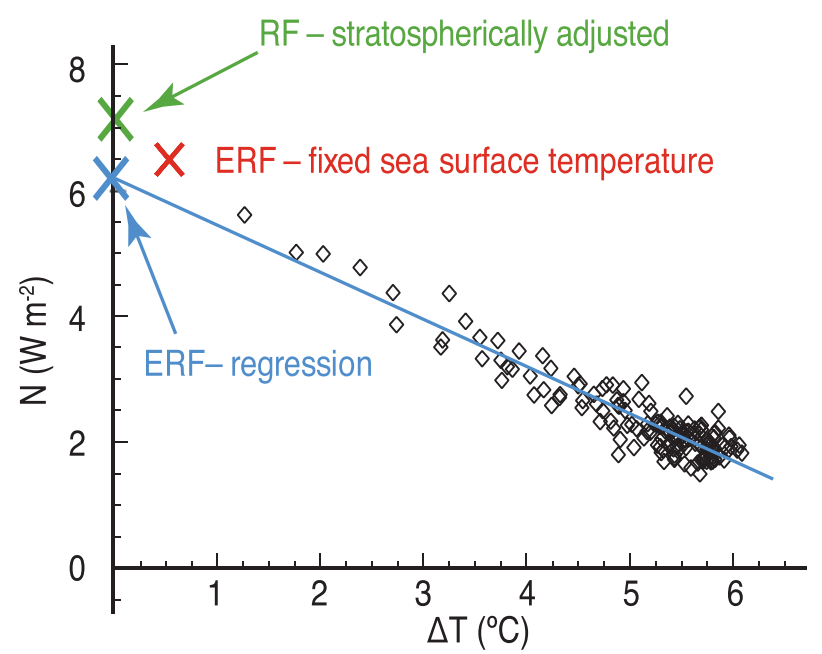

FIG. 4. Stratospherically adjusted RF and ERF estimates by regression and fixed-SST methods using instantaneous $4 \times \mathrm{CO}_{2}$ experiments for a typical CMIP5 climate model. The $N$ is the net radiative flux imbalance at TOA and $\boldsymbol{d} \overline{\mathbf{T}}$ is the global-mean surface temperature change. The green crisscross gives the stratospherically adjusted radiative forcing of $\mathrm{CO}_{2}$ quadrupling-7.1 $\mathrm{W} \mathrm{m}^{-2}$ in this model. This is estimated as the instantaneous net downward radiative flux change at the tropopause when $\mathrm{CO}_{2}$ is quadrupled. The black diamonds are annual means of the differences between the first 150 years of step $4 \times \mathrm{CO}_{2}$ and control simulations. The blue line is the regression fit to these points. Its $\boldsymbol{d} \overline{\mathbf{T}}$ intercept (blue crisscross) is the Gregory estimate of ERF (6.5 W m-2 in this model). The red crisscross is a 30 -yr mean difference of a pair of fixed SST runs: one with standard $\mathrm{CO}_{2}$ and one with quadrupled $\mathrm{CO}_{2}$. To make it consistent with our basic definition, it needs to be adjusted to $d \bar{T}$ by adding $0.5 \mathrm{~W} \mathrm{~m}^{-2}$, thereby removing the feedback contribution (dashed red line), giving a fixed-SST ERF estimate of 7.0 W m-2 for this model. Adapted from Fig. 7.2 of Boucher et al. (2013).

in which the $d \bar{T}=0$ intercept is the ERF (Gregory et al. 2004). The second or "fixed SST" method (sometimes called the Hansen method) diagnoses ERF, $d \bar{F}$, and $\bar{N}$ from a simulation, including the forcing agent, but with sea surface temperatures and sea ice prescribed to their unperturbed climatology (Cess and Potter 1988; Hansen et al. 2005; see also Fig. 1c).

The regression method implicitly defines adjustments as those changes that occur relatively soon (within a few years), including those mediated by regional variations in SST change. The latter are excluded by the fixed-SST approach, which does on the other hand include all other forcing-related adjustments no matter how long they take to occur (provided the simulation is long enough). The regression method can be thrown off by time-varying 
feedbacks, in which case $\bar{N}$ versus $d \bar{T}$ will not be a straight line. However, this method satisfies the principle of cleanly separating adjustments from global-mean temperature change $d \bar{T}$, whereas the fixed-SST method permits land temperature change, which contributes to $d \bar{T}$ and affects the air-sea temperature difference over oceans (see Kamae and Watanabe 2013; Shine et al. 2003; Vial et al. 2013). This enhances the global Planck response and triggers some warming-related changes, such as an increase in global atmospheric water vapor (Colman and McAvaney 2011), the effects of which should be subtracted out if one wishes to isolate true adjustments from changes that result from feedbacks.

These two methods are shown for a typical Coupled Model Intercomparison Project (CMIP) in Fig. 4. A third method that has been used in the literature for precipitation responses (examined further below) is to assume that the change during some limited time period (e.g., one year) following an abrupt forcing, compared to the climatology before, is due to adjustments. However, the $d \bar{T}$ during this period is substantial, making it difficult to quantitatively compare with the other approaches.

The regression-based ERF estimate from a single simulation is inherently noisier than the fixed-SST one and is best suited for global-mean responses rather than regional responses. However, it can be made more precise by averaging across an ensemble of at least 5-10 shorter coupled simulation pairs of 10-20 years in which the step change in $\mathrm{CO}_{2}$ from the control is made at different times to average over natural climate variability (e.g., Watanabe et al. 2012; see next section). The fixed-SST ERF estimate is naturally more robust to internal climate variability because it takes advantage of the long averaging time and the fact that the interannual ocean variability is either absent or identical in the perturbed and control simulations.

To the extent that the temperature-mediated response of the climate system is linear and invariant to the warming pattern, these methods should give almost identical results when the latter is corrected for the change in $d \bar{T}$ at fixed SST. As seen in Fig. 4, this is approximately true for global-mean quantities, but there are noteworthy differences.

In all CMIP phase 5 (CMIP5) models for which the needed output has been published, the fixed-SST $4 \times \mathrm{CO}_{2}$ ERF exceeds the regression-based one, usually by a statistically significant margin. This point has been obscured because the literature has reported the former without the aforementioned $\sim 0.5 \mathrm{~W} \mathrm{~m}^{-2}$ feedback correction for land warming. Applying this correction to the seven CMIP5 models in Table 1 of Andrews et al. (2012) reporting both estimates, the fixed-SST ERF exceeds the regression ERF by about $15 \%\left(0.2-1.6 \mathrm{~W} \mathrm{~m}^{-2}\right.$ at $4 \times \mathrm{CO}_{2}$, with a mean of $1 \mathrm{~W} \mathrm{~m}^{-2}$ ). The Hadley Centre Global Environment Model, version 2-Earth System (HadGEM2-ES) exhibits a particularly large discrepancy due to a somewhat nonlinear response of $\bar{N}$ to the warming $d \bar{T}$ during the first year or two. Andrews et al. (2012) traced this response to an increase over time in cloud shortwave radiative feedback over oceans. Since this increase seems to occur in many models, it merits further study.

Watanabe et al. (2012) showed in one model how an ENSO-like SST anomaly can set up in the first year or two after a $\mathrm{CO}_{2}$ increase due to weakening of the Walker circulation (see also Bony et al. 2013); this is an example of an adjustment not captured by the fixed-SST framework. In parts of the oceans with relatively shallow mixed layers, the SST can respond more rapidly than in others, leading to the emergence of fast changes in SST patterns, while the global $d \bar{T}$ is still small (Armour et al. 2013). These changes influence cloud and circulation patterns (see the next section), amplify the atmospheric adjustments, and can be aliased onto changes in global-mean cloud radiative effects in some models.

GCM-based estimates of the radiative forcing of anthropogenic aerosol on climate have often been based on a comparison of fixed-SST simulations with preindustrial and present-day aerosol emissions. These estimates are universally uncorrected for the associated change in global surface air temperature due to land temperature change; in principle, an approximately $1 \mathrm{~W} \mathrm{~m}^{-2}$ correction per kelvin of $d \bar{T}$ should be added to them to be fully consistent with the ERF paradigm. However, at least for one model checked [Community Atmosphere Model, version 5 (CAM5)], the surface air temperature change is less than $0.1 \mathrm{~K}$, so this correction is negligible for most purposes.

In summary, ERF is a construct designed to fit the global radiative response of a model as a linear function of $d \bar{T}$ over time scales of decades to a century. From this perspective, the regression ERF is preferable to the fixed-SST one, since it is based on precisely the linear fit that is used for global feedback analysis, but this fit is imperfect, especially if applied to regional responses to $d \bar{T}$ rather than global-mean ones. The difference in results between the two methods can be interpreted as an indicator of short-term deviations from linearity in the relation of $\bar{N}$ to $d \bar{T}$. Such deviations seem to arise from the knock-on effects of 
inhomogeneous surface warming. The attribution of this to adjustment or feedback is inherently ambiguous, should depend on the circumstances and goals of the analysis, and will be different between the two methods considered here.

PRECIPITATION. Rapid adjustments to $\bar{N}$ caused by $\mathrm{CO}_{2}$ and aerosol are difficult if not impossible to detect in observations. We can, however, look for these physical effects in quantities other than the TOA radiative flux. Notably, we can consider the direct impact of a $\mathrm{CO}_{2}$ change on precipitation in the absence of any global-mean (or ocean mean) $\bar{T}$ change. We should note, however, that because precipitation patterns are sensitive to small changes in the temperature pattern, we would expect regional precipitation changes to be relatively forcing dependent even in the absence of adjustments-for example, a forcing that causes warming asymmetrically distributed between the hemispheres shifts tropical rain maxima toward the hemisphere of greater warming (Seo et al. 2014). Thus, rapid adjustments alone may not explain all forcing-dependence of precipitation responses.

Possible adjustments of precipitation to aerosol perturbations (both radiative and cloud microphysical) are now well recognized in principle but are poorly understood, hence controversial. For instance, by absorbing solar radiation, increased black carbon aerosols will cause a slight decrease in global-mean precipitation for the same surface temperature (Andrews et al. 2010). However, regional precipitation changes may be more important and can occur far away from the aerosol that drives them (Wang 2013). Models suggest that, because of their heterogeneous heating of the atmosphere and surface, aerosol-radiation interactions can affect monsoons (Ramanathan et al. 2005; Lau et al. 2006), shift the intertropical convergence zone (Rotstayn and Lohmann 2002), and displace atmospheric jets poleward (Allen et al. 2012). Some of these studies have argued that these effects can be detected in observed rainfall trends. CCN-mediated effects on precipitation also have attracted great attention but are even more controversial (e.g., Tuttle and Carbone 2011; Tao et al. 2012).

Less recognized are the direct effects of solar or greenhouse gas perturbations on precipitation. $\mathrm{CO}_{2}$ warms and stabilizes the lower troposphere, slowing the global hydrological cycle for a given $\bar{T}$ (Allen and Ingram 2002; Andrews et al. 2010), and slowing and causing a redistribution of the tropical overturning circulation (Andrews et al. 2010; Wyant et al. 2012; Bony et al. 2013). The shifts in tropical rainfall associated with this effect make up a substantial part of the total circulation-driven rainfall change in climates simulated by the end of the twenty-first century (Bony et al. 2013). The change in global-mean rainfall is also nontrivial compared to that from warming. These effects on rainfall are somewhat more pronounced than those on TOA radiative balance, where adjustments appear to account for no more than $20 \%$ of global-mean $d \bar{T}$ in a multimodel average [though also contributing to forcing uncertainty (Forster et al. 2013; Vial et al. 2013)]. Much of the precipitation adjustment to $\mathrm{CO}_{2}$ occurs very rapidly-within a week (Fig. 5). Thus, precipitation adjustments to $\mathrm{CO}_{2}$ may stand a better chance of eventually being detectable in observations than would the TOA radiation adjustments.

Determining the spatial distribution of the precipitation adjustment is challenging because precipitation is highly variable on interannual and longer time scales and sensitive to gradients in tropical sea surface temperature. Unforced anomalies that happen to occur after a step increase in forcing will be confounded with adjustments, necessitating an ensemble average to obtain the latter accurately from abruptforcing scenarios (Fig. 6). Moreover, atmospheric responses to forcings can quickly drive changes to the surface oceans, especially near the equator, that can strongly amplify or otherwise alter regional precipitation responses (cf. Figs. 6a,b; see also Chadwick et al. 2014). Such knock-on responses (which also affect top-of-atmosphere radiation) should be regarded as part of the adjustment to the extent that they involve SST gradients rather than the global-mean $\bar{T}$, although again there is no unambiguous separation.

CONCLUSIONS. In response to changing concentrations of $\mathrm{CO}_{2}$ or other forcings, the climate system changes in ways that are independent of any global-mean surface temperature change, but that subsequently influence the global-mean radiation budget and, hence, surface temperature. These adjustments also appear to affect other climate quantities significantly-in particular, precipitation. They are physically significant, depend on the forcing agent, and need to be accounted for when computing the radiative forcing of the agent. Many of them develop on a time scale of days (Cao et al. 2012; Kamae and Watanabe 2012; Bony et al. 2013). Accounting more appropriately for adjustments offers new opportunities to better understand, predict, and evaluate impacts of different perturbations.

The fact that adjustments scale with the amplitude of the forcing rather than that of the global 
a) Precipitation change 1 day after quadrupling

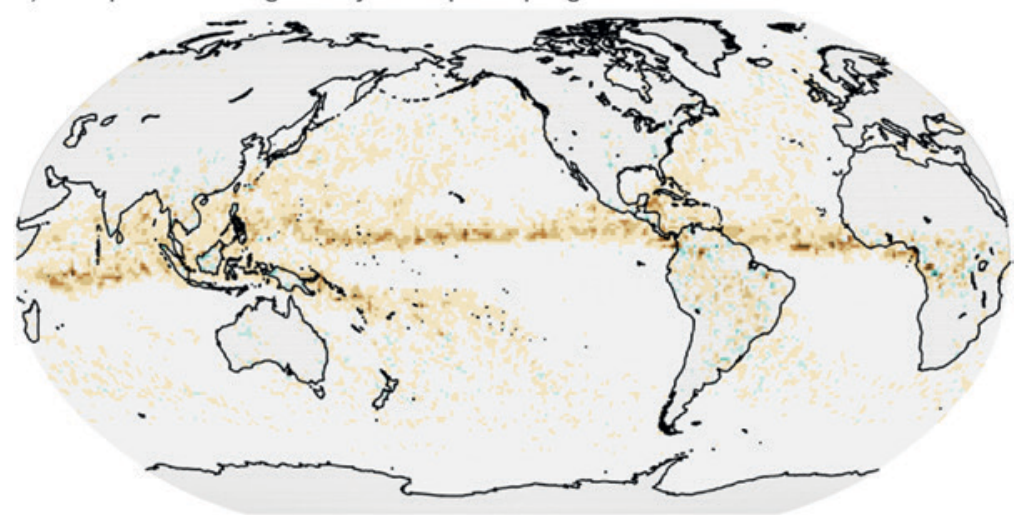

b) Precipitation change 5 days after quadrupling

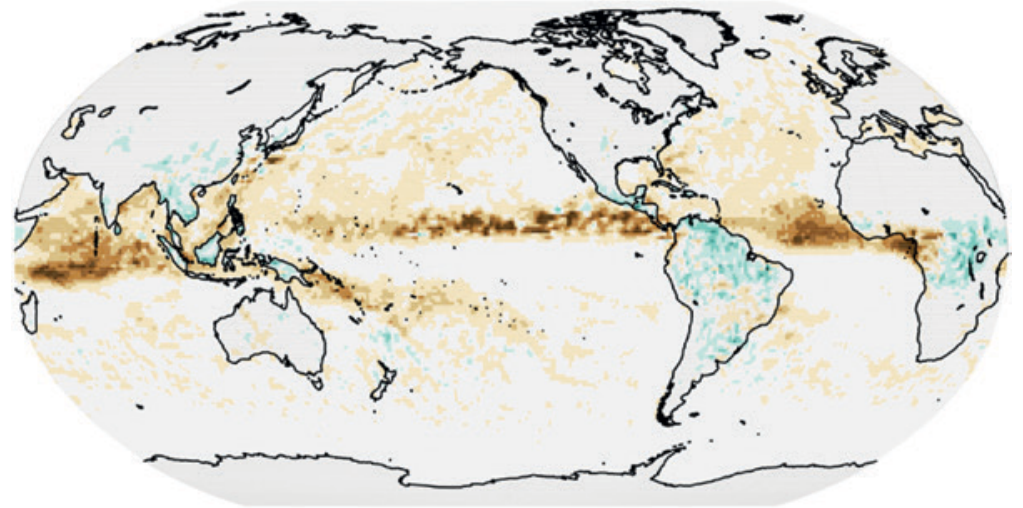

c) Precipitation change 10 days after quadrupling

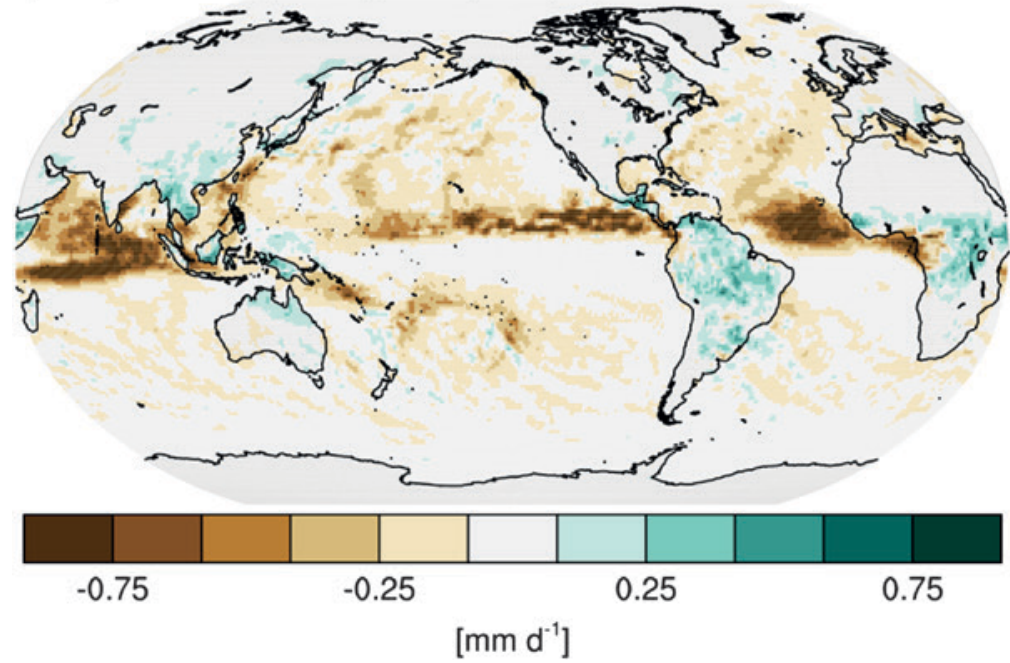

FIG. 5. Rapid development of the $\mathrm{CO}_{2}$-induced precipitation response $\left(\mathrm{mm} \mathrm{day}{ }^{-1}\right)$ as simulated by the European Centre for Medium-Range Weather Forecasts (ECMWF) Integrated Forecast System (IFS) model for Oct $201 \mathrm{I}$ upon instantaneous quadrupling of $\mathrm{CO}_{2}$. As $\mathrm{CO}_{2}$ increases, the reduction of the atmospheric radiative cooling warms the troposphere relative to the ocean surface and warms the surface relative to the atmosphere over land. This adjustment response, which takes place within a few days, reduces precipitation over ocean but enhances it over most land areas. Adapted from Bony et al. (2013). warming response means that even if global-mean temperature were for some reason very insensitive to forcing-owing to, for example, some hypothetical strong negative feedback from clouds - the adjustments would remain unaffected. It also implies that part of the climate response to forcing is independent of the long-standing uncertainty in climate sensitivity.

While the forcing-feedback paradigm has always been recognized as imperfect, such discrepancies have previously been attributed to variations in "efficacy" (Hansen et al. 1984), which did not clarify their nature. Decomposing the climate response into a forcing-specific adjustment and a $\bar{T}$-mediated response that is more forcing independent provides a clearer way of understanding climate changes, especially transient ones.

The adjustment concept needs to be fully integrated into energy budget studies (e.g., Otto et al. 2013). Estimates of radiative forcings and climate sensitivity ought to be defined consistently when observations are used to constrain estimates of the radiative forcings, climate sensitivity, or both quantities. The traditional climate sensitivity is actually the product of two quantities: the radiative forcing of a doubling of $\mathrm{CO}_{2}$ and a climate sensitivity parameter $\left[\mathrm{K}\left(\mathrm{W} \mathrm{m}^{-2}\right)^{-1}\right]$, where it has been assumed that the former is known exactly. In fact it is not, especially when adjustments are considered as part of the forcing (see Webb et al. 2013; Stevens and Schwartz 2012). Because adjustments make the forcing uncertain, future studies should distinguish between the traditional climate sensitivity, which depends on adjustments, and the climate sensitivity parameter, which does not.

This decomposition may clarify some past reports of feedbacks appearing to be state dependent, 
forcing dependent, or time dependent, although not all such complexities are likely be resolved and some variations in efficacy will remain. Studies already show that transient climate changes at arbitrary times while the system is out of equilibrium can be approximately recovered by adding the rapid adjustment to $\mathrm{CO}_{2}$ at that time to the (lagging) temperature-mediated response (Andrews et al. 2010). To a considerable extent this also works for multimodel-mean precipitation responses (Bony et al. 2013). This leads to a considerable simplification and will be useful to those exploring climate change using simple models that are only a function of global-mean radiative forcings (e.g., Huntingford and Cox 2000), especially if such models explore scenarios (e.g., overshooting of carbon targets, ramping up and down of greenhouse gas forcings) that stray from those for which they have been fitted to the behavior of a more detailed climate model.

This approach also helps us to understand and anticipate the limitations of potential geoengineering strategies. Idealized climate simulations of solar radiation management (Bala et al. 2008; Schmidt et al. 2012) show that when the warming due to $\mathrm{CO}_{2}$ increase is counteracted by a decrease in the solar constant, the warming-induced impacts are reversed to a large extent but adjustment responses may linger. In the case of precipitation, the rapid adjustment to the higher $\mathrm{CO}_{2}$ amount is not counteracted by a commensurate adjustment in response to lower solar radiation, leaving a net decrease in global-mean precipitation as well as larger residual changes at the regional level.

Indeed, changes to solar radiation, volcanic aerosol, and orbital properties are each likely to lead to distinct adjustments to global rainfall and regional climate patterns in addition to their common impact on global-mean temperature. Recognizing and understanding the adjustments may be crucial in helping to make sense of both present and past climate changes. For instance, accounting for adjustments helps interpret differences in the precipitation response to natural versus anthropogenic forcing (Liu et al. 2013).

Rapid adjustments involve rapid processes and may present an opportunity to use model evaluations on very short time scales to constrain processes that are also important for longer-term climate change. Such systematic weather-forecast type of verification has been suggested as a possible way to improve the representation of model processes (Brown et al. 2012), but it may also aid our understanding of the multiple adjustments associated with aerosol-cloud a) Abrupt $4 \times \mathrm{xO}_{2}$

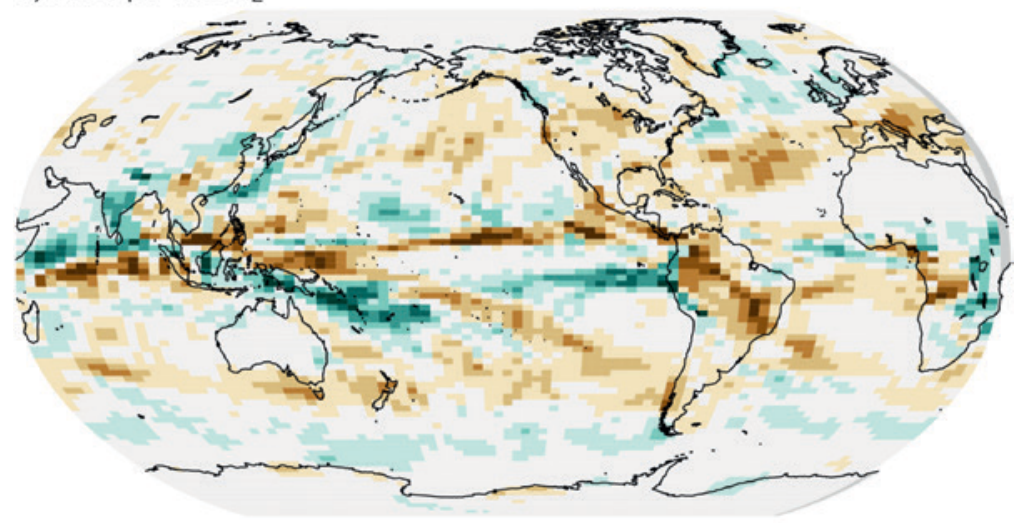

b) SSTClim $4 \times \mathrm{xO}_{2}$

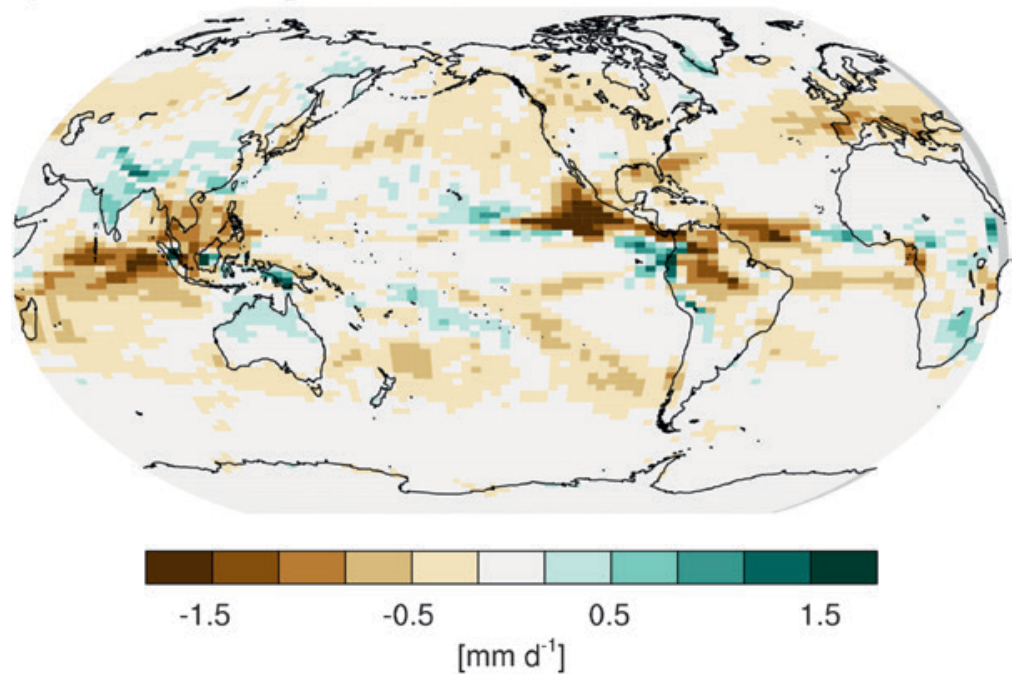

FIG. 6. Adjustment of precipitation to a quadrupling of $\mathrm{CO}_{2}$ estimated two ways, using a single climate model [Institut Pierre-Simon Laplace Coupled Model, version 5A (IPSL-CM5A)]. (a) Difference between the first year after quadrupling and the control climatology, averaged over an ensemble of $\mathbf{I}$ realizations (this result, which is similar to that obtained by the regression method on the ensemble-mean time series, shows strong regional influences in the tropics from SST changes). (b) Change with SST held fixed everywhere, averaged over 12 years. Note the scale has double the range of that in Fig. 5. 
interactions (Stevens and Boucher 2012) or the physical processes that control the direct effect of $\mathrm{CO}_{2}$ on circulation and precipitation (Bony et al. 2013). Since rapid adjustments closely track the forcing variations in time, they may contribute substantially to initial transient climate changes even if they make up a relatively small part of the long-term equilibrium response. This may offer an opportunity to better detect and disentangle the relative role of different forcings on climate, including on regional responses, and thus to facilitate detection and attribution studies. There are thus two broad reasons for future studies to distinguish more carefully between forcing-specific adjustments and temperature-driven feedback responses: to clarify our understanding of past climate changes and to exploit what the relationships among various adjustment and feedback responses may be able to tell us about the climate system and how it will respond in the future.

ACKNOWLEDGMENTS. We thank N. Huneeus for his generous help leading to Fig. 5. CB acknowledges support from NOAA Grant NA13OAR4310104. PF was supported by a Royal Society Wolfson Research Merit Award and EPSRC EP/I014721/1. Additional support (for BS and SB) was provided through funding from the European Union Seventh Framework Programme (FP7/2007-2013) under Grant Agreement 244067.

\section{REFERENCES}

Allen, M. R., and W. J. Ingram, 2002: Constraints on future changes in climate and the hydrologic cycle. Nature, 419, 224-232, doi:10.1038/nature01092.

Allen, R. J., S. C. Sherwood, J. R. Norris, and C. S. Zender, 2012: Recent Northern Hemisphere tropical expansion primarily driven by black carbon and tropospheric ozone. Nature, 485, 350-354, doi:10.1038 /nature11097.

Andrews, T., and P. M. Forster, 2008: $\mathrm{CO}_{2}$ forcing induces semi-direct effects with consequences for climate feedback interpretations. Geophys. Res. Lett., 35, L04802, doi:10.1029/2007GL032273.

— - _ O. Boucher, N. Bellouin, and A. Jones, 2010: Precipitation, radiative forcing and global temperature change. Geophys. Res. Lett., 37, L14701, doi:10.1029/2010GL043991.

_ J. J. Mregory, M. J. Webb, and K. E. Taylor, 2012: Forcing, feedbacks and climate sensitivity in CMIP5 coupled atmosphere-ocean climate models. Geophys. Res. Lett., 39, L09712, doi:10.1029/2012GL051607.

Armour, K. C., C. M. Bitz, and G. H. Roe, 2013: Time-varying climate sensitivity from regional feedbacks. J. Climate, 26, 4518-4534, doi:10.1175 /JCLI-D-12-00544.1.

Arneth, A., and Coauthors, 2010: Terrestrial biogeochemical feedbacks in the climate system. Nat. Geosci., 3, 525-532, doi:10.1038/ngeo905.

Bala, G., P. B. Duffy, and K. E. Taylor, 2008: Impact of geoengineering schemes on the global hydrological cycle. Proc. Natl. Acad. Sci. USA, 105, 7664-7669, doi:10.1073/pnas.0711648105.

Bates, J. R., 2007: Some considerations of the concept of climate feedback. Quart. J. Roy. Meteor. Soc., 133, 545-560, doi:10.1002/qj.62.

_- 2012: Climate stability and sensitivity in some simple conceptual models. Climate Dyn., 38, 455-473, doi:10.1007/s00382-010-0966-0.

Bony, S., G. Bellon, D. Klocke, S. Sherwood, S. Fermepin, and S. Denvil, 2013: Robust direct effect of carbon dioxide on tropical circulation and regional precipitation. Nat. Geosci., 6, 447-451, doi:10.1038/ ngeo1799.

Boucher, O., and Coauthors, 2013: Clouds and aerosols. Climate Change 2013: The Physical Science Basis, T. F. Stocker, et al., Eds., Cambridge University Press, 571-657.

Brown, A., S. Milton, M. Cullen, B. Golding, J. Mitchell, and A. Shelly, 2012: Unified modeling and prediction of weather and climate: A 25-year journey. Bull. Amer. Meteor. Soc., 93, 1865-1877, doi:10.1175 /BAMS-D-12-00018.1.

Caballero, R., and M. Huber, 2013: State-dependent climate sensitivity in past warm climates and its implications for future climate projections. Proc. Natl. Acad. Sci. USA, 110, 14 162-14 167, doi:10.1073 /pnas.1303365110.

Cao, L., G. Bala, and K. Caldeira, 2012: Climate response to changes in atmospheric carbon dioxide and solar irradiance on the time scale of days to weeks. Environ. Res. Lett., 7, 034015, doi:10.1088/1748 $-9326 / 7 / 3 / 034015$.

Cess, R. D., and G. L. Potter, 1988: A methodology for understanding and intercomparing atmospheric climate feedback processes in general circulation models. J. Geophys. Res., 93, 8305-8314, doi:10.1029 /JD093iD07p08305.

—-, and Coauthors, 1990: Intercomparison and interpretation of climate feedback processes in 19 atmospheric general circulation models. J. Geophys. Res., 95, 16601-16615, doi:10.1029/JD095iD10p16601.

Chadwick, R., P. Good, T. Andrews, and G. Martin, 2014: Surface warming patterns drive tropical rainfall pattern responses to $\mathrm{CO}_{2}$ forcing on all timescales. Geophys. Res. Lett., 41, 610-615, doi:10.1002 /2013GL058504. 
Colman, R. A. and B. J. McAvaney, 2009: Climate feedbacks under a very broad range of forcing. Geophys. Res. Lett., 36, L01702, doi:10.1029/2008GL036268.

—, and —-, 2011: On tropospheric adjustment to forcing and climate feedbacks. Climate Dyn., 36, 1649-1658, doi:10.1007/s00382-011-1067-4.

Crucifix, M., 2006: Does the Last Glacial Maximum constrain climate sensitivity? Geophys. Res. Lett., 33, L18701, doi:10.1029/2006GL027137.

Dickinson, R. E., and K. J. Schaudt, 1998: Analysis of timescales of response of a simple climate model. J. Climate, 11, 97-106, doi:10.1175/1520 -0442(1998)0112.0.CO;2.

Dong, B. W., J. M. Gregory, and R. T. Sutton, 2009: Understanding land-sea warming contrast in response to increasing greenhouse gases. Part I: Transient adjustment. J. Climate, 22, 3079-3097, doi:10.1175/2009JCLI2652.1.

Doutriaux-Boucher, M., M. J. Webb, J. M. Gregory, and O. Boucher, 2009: Carbon dioxide induced stomatal closure increases radiative forcing via a rapid reduction in low cloud. Geophys. Res. Lett., 36, L02703, doi:10.1029/2008GL036273.

Fels, S. B., J. D. Mahlman, M. D. Schwarzkopf, and R. W. Sinclair, 1980: Stratospheric sensitivity to perturbations in ozone and carbon-dioxide: Radiative and dynamical response. J. Atmos. Sci., 37, 2265-2297, doi:10.1175/1520-0469(1980)0372.0.CO;2.

Forster, P. M., T. Andrews, P. Good, J. M. Gregory, L. S. Jackson, and M. Zelinka, 2013: Evaluating adjusted forcing and model spread for historical and future scenarios in the CMIP5 generation of climate models. J. Geophys. Res. Atmos., 118, 1139-1150, doi:10.1002 /jgrd.50174.

Gregory, J. M., and M. Webb, 2008: Tropospheric adjustment induces a cloud component in $\mathrm{CO}_{2}$ forcing. $J$. Climate, 21, 58-71, doi:10.1175/2007JCLI1834.1.

— ing radiative forcing and climate sensitivity. Geophys. Res. Lett., 31, L03205, doi:10.1029/2003GL018747.

_ C. D. Jones, P. Cadule, and P. Friedlingstein, 2009: Quantifying carbon cycle feedbacks. J. Climate, 22, 5232-5250, doi:10.1175/2009JCLI2949.1.

Hansen, J., A. Lacis, D. Rind, G. Russell, P. Stone, I. Fung, R. Ruedy, and J. Lerner, 1984: Climate sensitivity: Analysis of feedback mechanisms. Climate Processes and Climate Sensitivity, Geophys. Monogr., Vol. 29, Amer. Geophys. Union, 130-163.

_- M. Sato, and R. Ruedy, 1997: Radiative forcing and climate response. J. Geophys. Res., 102, 6831-6864, doi:10.1029/96JD03436.

_ , and Coauthors, 2005: Efficacy of climate forcings. J. Geophys. Res., 110, D18104, doi:10.1029/2005JD005776.
Houghton, J. T., G. J. Jenkins, and J. J. Ephraums, Eds., 1990: Climate Change: The IPCC Scientific Assessment. Cambridge University Press, 410 pp.

Huntingford, C., and P. M. Cox, 2000: An analogue model to derive additional climate change scenarios from existing GCM simulations. Climate Dyn., 16, 575-586, doi:10.1007/s003820000067.

Jarvis, A., and S. Li, 2011: The contribution of timescales to the temperature response of climate models. Climate Dyn., 36, 523-531, doi:10.1007/s00382-010 -0753-y.

Kamae, Y., and M. Watanabe, 2012: On the robustness of tropospheric adjustment in CMIP5 models. Geophys. Res. Lett., 39, L23808, doi:10.1029/2012GL054275.

$\longrightarrow$, and — 2013: Tropospheric adjustment to increasing $\mathrm{CO}_{2}$ : Its timescale and the role of land-sea contrast. Climate Dyn., 41, 3007-3024, doi:10.1007 /s00382-012-1555-1.

Lau, K. M., M. K. Kim, and K. M. Kim, 2006: Asian summer monsoon anomalies induced by aerosol direct forcing: The role of the Tibetan Plateau. Climate Dyn., 26, 855-864, doi:10.1007/s00382-006-0114-z.

Liu, J., B. Wang, M. A. Cane, S. Y. Yim, and J. Y. Lee, 2013: Divergent global precipitation changes induced by natural versus anthropogenic forcing. Nature, 493, 656-659, doi:10.1038/nature11784.

Lohmann, U., and Coauthors, 2010: Total aerosol effect: Radiative forcing or radiative flux perturbation? Atmos. Chem. Phys., 10, 3235-3246, doi:10.5194 lacp-10-3235-2010.

Mercado, L. M., N. Bellouin, S. Sitch, O. Boucher, C. Huntingford, M. Wild, and P. M. Cox, 2009: Impact of changes in diffuse radiation on the global land carbon sink. Nature, 458, 1014-1017, doi:10.1038 /nature07949.

National Research Council, 2005: Radiative Forcing of Climate Change: Expanding the Concept and Addressing Uncertainties. The National Academies Press, 224 pp.

Otto, A., and Coauthors, 2013: Energy budget constraints on climate response. Nat. Geosci., 6, 415-416, doi:10.1038/ngeo1836.

Raes, F., H. Liao, W.-T. Chen, and J. H. Seinfeld, 2010: Atmospheric chemistry-climate feedbacks. J. Geophys. Res., 115, D12121, doi:10.1029/2009JD013300.

Ramanathan, V., and Coauthors, 2005: Atmospheric brown clouds: Impacts on South Asian climate and hydrological cycle. Proc. Natl. Acad. Sci. USA, 102, 5326-5333, doi:10.1073/pnas.0500656102.

Rotstayn, L. D., and J. E. Penner, 2001: Indirect aerosol forcing, quasi forcing, and climate response. J. Climate, 14, 2960-2975, doi:10.1175/1520 $-0442(2001) 0142.0 . \mathrm{CO} ; 2$. 
- , and U. Lohmann, 2002: Tropical rainfall trends and the indirect aerosol effect. J. Climate, 15, 2103-2116, doi:10.1175/1520-0442(2002)0152.0.CO;2.

Schlesinger, M. E., and J. F. B. Mitchell, 1987: Climate model simulations of the equilibrium climatic response to increased carbon dioxide. Rev. Geophys., 25, 760-798, doi:10.1029/RG025i004p00760.

Schmidt, H., and Coauthors, 2012: Solar irradiance reduction to counteract radiative forcing from a quadrupling of $\mathrm{CO}_{2}$ : Climate responses simulated by four Earth system models. Earth Syst. Dyn., 3, 63-78, doi:10.5194/esd-3-63-2012.

Senior, C. A., and J. F. B. Mitchell, 2000: The timedependence of climate sensitivity. Geophys. Res. Lett., 27, 2685-2688, doi:10.1029/2000GL011373.

Seo, J., S. M. Kang, and D. M. W. Frierson, 2014: Sensitivity of intertropical convergence zone movement to the latitudinal position of thermal forcing. $J$. Climate, 27, 3035-3042, doi:10.1175/JCLI-D-13 -00691.1.

Shine, K. P., J. Cook, E. J. Highwood, and M. M. Joshi, 2003: An alternative to radiative forcing for estimating the relative importance of climate change mechanisms. Geophys. Res. Lett., 30, 2047, doi:10.1029 /2003GL018141.

Soden, B. J., and I. M. Held, 2006: An assessment of climate feedbacks in coupled ocean-atmosphere models. J. Climate, 19, 3354-3360, doi:10.1175 /JCLI3799.1.

Stevens, B., and O. Boucher, 2012: The aerosol effect: An essential pursuit. Nature, 490, 40-41, doi:10.1038/490040a.

Stevens, B., and S. E. Schwartz, 2012: Observing and modeling Earth's energy flows. Surv. Geophys., 33, 779-816, doi:10.1007/s10712-012-9184-0.
Tao, W. K., J. P. Chen, Z. Q. Li, C. Wang, and C. D. Zhang, 2012: Impact of aerosols on convective clouds and precipitation. Rev. Geophys., 50, RG2001, doi:10.1029/2011RG000369.

Tuttle, J. D., and R. E. Carbone, 2011: Inferences of weekly cycles in summertime rainfall. J. Geophys. Res., 116, D20213, doi:10.1029/2011JD015819.

Vial, J., J.-L. Dufresne, and S. Bony, 2013: On the interpretation of inter-model spread in CMIP5 climate sensitivity estimates. Climate Dyn., 41, 3339-3362, doi:10.1007/s00382-013-1725-9.

Wang, C., 2013: Impact of anthropogenic absorbing aerosols on clouds and precipitation: A review of recent progresses. Atmos. Res., 122, 237-249, doi:10.1016/j.atmosres.2012.11.005.

Watanabe, M., H. Shiogama, M. Yoshimori, T. Ogura, T. Yokohata, H. Okamoto, S. Emori, and M. Kimoto, 2012: Fast and slow timescales in the tropical lowcloud response to increasing $\mathrm{CO}_{2}$ in two climate models. Climate Dyn., 39, 1627-1641, doi:10.1007 /s00382-011-1178-y.

Webb, M. J., F. H. Lambert, and J. M. Gregory, 2013: Origins of differences in climate sensitivity, forcing and feedback in climate models. Climate Dyn., 40, 677-707, doi:10.1007/s00382-012-1336-x.

Wyant, M. C., C. S. Bretherton, P. N. Blossey, and M. Khairoutdinov, 2012: Fast cloud adjustment to increasing $\mathrm{CO}_{2}$ in a superparameterized climate model. J. Adv. Model. Earth Syst., 4, M05001, doi:10.1029 /2011MS000092.

Zelinka, M., S. Klein, K. Taylor, T. Andrews, M. Webb, J. Gregory, and P. Forster, 2013: Contributions of different cloud types to feedbacks and rapid adjustments in CMIP5. J. Climate, 26, 5007-5027, doi:10.1175/JCLI -D-12-00555.1. 